\title{
Quality of Nursing Care Provided to Patients in the Operating Room, Based on Ministry of Health Standard of Care
}

\author{
OLA Y. HASSAN, M.Sc.; MAGDA A. EL-MOLLA, D.N.Sc. and NAGAT EL-MORSY, D.N.Sc. \\ The Department of Nursing Administration, Faculty of Nursing, Cairo University
}

\begin{abstract}
Background: Nurses play an important role in preserving the health of the patients, and one of a very critical area of nursing that can be exciting and provide a lot of direct patient care is working as an operating room nurse. So the operation nurse must be highly qualified to provide the patient with high quality nursing care.
\end{abstract}

Aim: This study assessed the quality of nursing care provided to patients in the operating room at Al-Ahrar Zagazig General Hospital.

Design: A descriptive cross-sectional design was utilized.

Sample: A sample of 40 nurses working in the operating room in two shifts, for observation of their performance as (scrub and circulating).

Setting: The study was conducted from eleven operating rooms Al-Ahrar Zagazig General in the Hospital.

Methods: Used two checklists: Inventory checklist for infrastructure, environmental safety and presence of policies and records; and an observation checklist for scrub and circulating nurse performance.

Results: The results demonstrated major deficiencies in OR general policies, although the infrastructure was generally adequate. Scrub nurses' performance is mostly inadequate, but is better compared with circulating nurses. It is influenced nurses' personal and job characteristics.

Conclusion: There was low on the performance of nurses due the absence of clear regulations or guidelines and common procedures as well as the absence of continuous training and education programs for the nurses.

Recommendation: Create a clear written job description, and provide continuous training to improve communication and additional skills.

Key Words: Quality - Nursing care-Operating room.

\section{Introduction}

WITH the advent of globalization and the competitive market, the emphasis on quality has increased.

Correspondence to: Dr. Ola Y. Hassan, The Department of Nursing Administration, Faculty of Nursing, Cairo University
Quality has become the most important single factor for the survival and success of today's companies. Customer demands for better products and services at the lowest possible costs have put tremendous pressure on firms to improve the quality of products, services, and processes to compete in the market and improve business results [1]. In this respect, health care quality has to meet the expectations of many groups of customers, including patients and their families, physicians, organizations, regulators, payers, and communities. In thinking about medical quality, the place to start is with Florance Nightingals (1820-1910), an English social reformer and statistical. Nightingale can be credited with creating the framework for quality management, using data as the bases for graphics about monthly improvements in mortality associated with her sanitary reforms [2]

Now, healthcare qualities are guided by the degree to which care, treatment, or services for individuals and population increase the likelihood of desired health or behavioral health outcomes. The service should be evaluated regarding its appropriateness, efficacy, efficiency, timeliness, accessibility and continuity of care in addition to the safety of the care environment and the individual's personal values, practices and beliefs [3] Quality and related standards are of utmost importance in the Operating Room (OR). This is a specialized room where the actual surgery takes place, usually a part of the restricted area of the surgical suite [4]

Nurses play an integral role in the health care system. This is why they have been correctly referred to as the heart of health care [5]. They take a much more active and independent role in providing the health care services. Nevertheless, nursing practice must support and be supported by 
activities in practice, education, research, and management [6].

\section{Significance of the study:}

Improving the quality of patient care services in hospitals is a vital and necessary activity [7] Operating room should provide a role in which surgical procedure can be undertaken with maximum safety to the patient [8]

The main significance of the application of quality standards in operating theaters: Is to help ensure that the nursing staff always follows a few important steps to ensure the safety and then reduce to a minimum risks that can be avoided and threaten the life and health of patients undergoing surgical operations.

The result of this study can be used as a source for future staff development training program in hospitals. Also, it can be used to correct the missing items or policies in operating rooms.

\section{Aim of the study:}

Assess the quality of nursing care provided to patients in the operating room at Al-Ahrar Zagazig General Hospital.

\section{Research question:}

What is the quality of nursing care provided to the patient in the operating room at Al-Ahrar Zagazig General Hospital?

\section{Subjects and Methods}

\section{Research design:}

A descriptive cross sectional design was used in conducting the study.

\section{Setting:}

The study was conducted in all operating rooms at Al-Ahrar Zagazig General Hospital, and data collection was completed over a six month period starting august (2015) to January (2016).

Subjects: The number of the study sample was 40 nurses.

\section{Tools of data collection:}

\section{The first part:}

Inventory checklist. The tool is divided into two parts: The 1 st part divided into three sections:

The 1 st section covered the demographic and work related data about the head nurse such as age, gender, and qualification.

The 2 nd section covered the assessment of policies in the operating room. Its items were to be answered by the head nurses, and observed by the researcher. The checklist comprised (39) policies divided into: (12 items) for the general policies of operating room, (12 items) for infection control policies in the operating room, (9 items) for safety policies in the operating room, and (6 items) of records and components of it.

The $3^{\text {rd }}$ section was for assessment of the structural criteria of operating rooms. The checklist comprised (39) structural criteria items divided into the following four subgroups of infrastructure standards: General specification (13 items and subitems), equipment (17 items and sub-items), environmental safety (7 items).

\section{The second part:}

Observational checklists categorized into 3 major sections.

The 1 st section covered the demographic and work related data of the study sample, as a working room (specialty), age, gender, and a nursing qualification, years of experience.

The $2^{\text {nd }}$ section covered the performance of scrub nurse: Contains (32 items and sub-items) that assess the performance of nurses, before, during and after the operation through the invasive procedure such as infection control, nursing procedure, surgical safety.

The 3 rd section covered the performance of the circulating nurse: Contains (51 items and subitems) that assess the performance of nurses, before, during and after the operation through the procedure such as infection control, nursing procedure, surgical safety, workplace safety.

\section{Data collection:}

- An official permission was obtained from the director of Al-Ahrar Zagazig General Hospital, the director of nursing service administration.

- The tools were reviewed by a panel of experts consisted of five nursing faculty members from Faculty of Nursing, Cairo University in the Medical Surgical Department to be tested for its content validity.

- The investigator contacted to the nurses to explain the purpose and procedure of the study and determine the available time to collect data.

- The observation was made during morning, and evening shifts.

- Data collection was completed over a six month period starting august (2015) to January (20 16). 


\section{Ethical consideration:}

Before commencing the study, ethical approval was granted from the Research Ethics Committee in which the study took place. The researchers ensured that the correct procedures were undertaken concerning informed consent, autonomy, anonymity and the maintenance of confidentiality.

\section{Statistical analysis:}

Upon completion of data collection, the data were scored, tabulated and statistically analyzed using the "Statistical Package for the Social Science" (SPSS) Version 20 for analysis. Data were presented using descriptive statistics in the form of the frequencies and percentages for qualitative variables, and means and standard deviations and medians for quantitative variables. Quantitative continuous data were compared using the nonparametric Mann-Whitney or Kruskal-Wallis test. Statistical significance was considered at $p$-value $<0.05$

\section{Results}

Table (1) showed that scrub/circulating nurses were mostly females $(87.5 \%)$. Their age ranged between 23 and 43 years, with a median 27.0 years. Less than a half of them $(42.5 \%)$ were holding a bachelor degree in nursing. Their experience ranged between 1 and 25 years, with a median 3.0 years.

Table (1): Demographic and work related characteristics scrub/ circulating nurses $(\mathrm{N}=40)$.

\begin{tabular}{|c|c|c|}
\hline Demographic characteristics & Frequency & Percent \\
\hline \multicolumn{3}{|l|}{ Age: } \\
\hline$<30$ & 32 & 80.0 \\
\hline $30+$ & 8 & 20.0 \\
\hline Range & \multicolumn{2}{|c|}{$23.0-43.0$} \\
\hline Mean \pm SD & \multicolumn{2}{|c|}{$27.6 \pm 3.5$} \\
\hline Median & \multicolumn{2}{|c|}{27.0} \\
\hline \multicolumn{3}{|l|}{ Gender: } \\
\hline Male & 5 & 12.5 \\
\hline Female & 35 & 87.5 \\
\hline \multicolumn{3}{|l|}{ Nursing qualification: } \\
\hline Technical school of nursing & 23 & 57.5 \\
\hline Bachelor & 17 & 42.5 \\
\hline \multicolumn{3}{|l|}{ Years experience in nursing: } \\
\hline$<5$ & 22 & 55.0 \\
\hline $5-$ & 15 & 37.5 \\
\hline $10+$ & 3 & 7.5 \\
\hline Range & \multicolumn{2}{|c|}{$1.0-25.0$} \\
\hline Mean \pm SD & \multicolumn{2}{|c|}{$4.6 \pm 4.4$} \\
\hline Median & \multicolumn{2}{|c|}{3.0} \\
\hline
\end{tabular}

Table (2) indicated a wide variation in scrub nurses' performance of infection control before the operation. Thus, all of them $(100 \%)$ were wearing dedicated to the operating room, and almost all of them $(97.5 \%)$ washed their hands immediately prior to gowning. On the other hand, none of them made sure all team members carried out the correct hand wash. As for the performance of the procedure before the operation, only the selection of instruments, equipment, and supplies appropriate for the surgery was performed by all of them. Meanwhile, a half or less of them were observed to perform the other three items.

Table (2): Percentage distribution of scrub nurses' performance before operating room $(\mathrm{N}=40)$.

\begin{tabular}{|c|c|c|}
\hline \multirow{2}{*}{ Scrub nurses' performance } & \multicolumn{2}{|c|}{ Done } \\
\hline & $\mathrm{N}$ & $\%$ \\
\hline \multicolumn{3}{|l|}{ Before operation: } \\
\hline \multicolumn{3}{|l|}{ Infection control: The scrub nurse: } \\
\hline $\begin{array}{l}\text { - Makes sure of instruments/supplies sterilization } \\
\text { before operation. }\end{array}$ & 34 & 85.0 \\
\hline - Wears shoes dedicated to the operating room. & 40 & 100.0 \\
\hline - Wear a head cover. & 14 & 35.0 \\
\hline $\begin{array}{l}\text { - Wear a mask properly (mask covers the nose } \\
\text { and mouth completely and securely). }\end{array}$ & 12 & 30.0 \\
\hline - Takes off own jewelry before washing hands. & 20 & 50.0 \\
\hline - Washing hands in the right way. & 15 & 37.0 \\
\hline - Washing hands immediately prior to gowning. & 39 & 97.5 \\
\hline $\begin{array}{l}\text { - Makes sure all team members carry out the } \\
\text { correct hand wash. }\end{array}$ & 0 & 0.0 \\
\hline \multicolumn{3}{|l|}{ Procedure before operation: The scrub nurse: } \\
\hline $\begin{array}{l}\text { - Select instruments, equipment, supplies } \\
\text { appropriate for the surgery. }\end{array}$ & 40 & 100.0 \\
\hline $\begin{array}{l}\text { - Count disposal instruments and supplies with } \\
\text { circulating nurse. }\end{array}$ & 20 & 50.0 \\
\hline $\begin{array}{l}\text { - Counts the cables of diathermy with circulating } \\
\text { nurse. }\end{array}$ & 9 & 22.5 \\
\hline - Checks the diathermy plate is applied correctly. & 18 & 45.0 \\
\hline
\end{tabular}

Table (3) showed that all of scrub nurses' $(100 \%)$ performed most items of infection control before operation. There were two exceptions related to helping doctors in wearing the protective barrier equipment $(7.5 \%)$, and putting sterile dressing on the operation site $(20.0 \%)$. Regarding to the performance of the procedure during the operation, two items was performed by all of them (100\%) related to provide instruments, sutures, supplies to the surgeon; and rearranges the instruments on the surgical table. Conversely, only one (20\%) nurse was observed to perform to put used gauze and sponges (abdominal towels) in a special container. Concerning the performance of surgical safety (sign-out), the same table indicated deficiency in all the items. This was particularly evident in relation to the item of counting gauze, sponges, and instruments before closing the skin with the surgeon and circulating nurse. 
Table (3): Percentage distribution of scrub nurses' performance during operating room $(\mathrm{N}=40)$.

\begin{tabular}{|c|c|c|}
\hline \multirow{2}{*}{ Scrub nurses' performance } & \multicolumn{2}{|c|}{ Done } \\
\hline & $\mathrm{N}$ & $\%$ \\
\hline \multicolumn{3}{|l|}{ During operation: } \\
\hline - Wears the gown dedicated to operating room. & 40 & 100.0 \\
\hline - Wears gloves properly. & 40 & 100.0 \\
\hline - Prepares the sterile field. & 40 & 100.0 \\
\hline $\begin{array}{l}\text { - Set up sterile table(s) with instruments and other } \\
\text { supplies needed for the procedure. }\end{array}$ & 40 & 100.0 \\
\hline $\begin{array}{l}\text { - Helps doctor in wearing protective barrier } \\
\text { equipment. }\end{array}$ & 3 & 7.5 \\
\hline - Prepare sterile dressing. & 40 & 100.0 \\
\hline - Puts sterile dressing on the operation site & 8 & 20.0 \\
\hline \multicolumn{3}{|l|}{ Procedure during operation: the scrub nurse: } \\
\hline $\begin{array}{l}\text { - Provides instruments, sutures, and supplies to } \\
\text { the surgeon. }\end{array}$ & 40 & 100.0 \\
\hline - Rearranges the instruments on surgical table. & 40 & 100.0 \\
\hline $\begin{array}{l}\text { - Puts used gauze and sponges (abdominal towels) } \\
\text { in special container. }\end{array}$ & 1 & 2.5 \\
\hline \multicolumn{3}{|l|}{ Surgical safety (sign-out): The scrub nurse: } \\
\hline $\begin{array}{l}\text { - Counts gauze and sponges before closing the } \\
\text { peritoneum with the surgeon and circulating } \\
\text { nurse. }\end{array}$ & 27 & 67.5 \\
\hline $\begin{array}{l}\text { - Counts instruments before closing the peritoneum } \\
\text { with the surgeon and circulating nurse. }\end{array}$ & 21 & 52.5 \\
\hline $\begin{array}{l}\text { - Counts gauze, sponges, and instruments before } \\
\text { closing the skin with the surgeon and circulating } \\
\text { nurse. }\end{array}$ & 15 & 37.5 \\
\hline
\end{tabular}

Table (4) indicated some variability in scrub nurses' performance of infection control after the operation. It regarded between (57.5\%) for removing gown before exit from operating room to $(92.5 \%)$ for putting sharps in their special containers. As for the performance of surgical safety after the operation, the table showed that almost all scrub nurses were observed to collect specimens and give them to circulating nurse $(95.0 \%)$. On the contrary, only $(42.5 \%)$ of them collected towels, covers and put them in a special container.

Table (4): Percentage distribution of Scrub nurses' performance after operating room $(\mathrm{N}=40)$.

\begin{tabular}{lrr}
\hline & \multicolumn{2}{c}{ Done } \\
\cline { 2 - 3 } Scrub nurses' performance & $\mathrm{N}$ & $\%$ \\
\hline $\begin{array}{l}\text { After operation: } \\
\text { Infection control: The scrub nurse: }\end{array}$ & & \\
- Puts the sharps in their special container. & 37 & 92.5 \\
- Puts surgical instruments in container to send & 30 & 75.0 \\
$\quad$ to central sterilization. & 35 & 87.5 \\
- Removes gloves before exit from operating & & \\
$\quad$ room. & 23 & 57.5 \\
- Removes gown before exit from operating room. \\
- Wash hands after removing of protective barrier \\
$\quad$ equipment.
\end{tabular}

As illustrated (Table 5), the performance of scrub nurses was generally low. It was lowest during the operation (20\%), particularly regarding the performance of the procedure before operation $(5 \%)$. On the other hand, the best performance was after the operation, although less than half of the scrub nurses had adequate total performance after the operation $(45 \%)$.

Table (5): Total percentage distribution of scrub nurses' performance $(\mathrm{N}=40)$.

\begin{tabular}{lll}
\hline & \multicolumn{2}{c}{ Done } \\
\cline { 2 - 3 } Scrub nurses' performance & $\mathrm{N}$ & $\%$ \\
\hline Before operation: & & \\
- Infection control. & 9 & 22.5 \\
• Procedure before operation. & 15 & 37.5 \\
- Total before. & 11 & 27.5 \\
During operation: & & \\
• Infection control. & 9 & 22.5 \\
• Procedure during operation. & 2 & 5.0 \\
- Surgical safety. & 14 & 35.0 \\
- Total during. & 8 & 20.0 \\
After operation: & & \\
• Infection control. & 25 & 62.5 \\
• Surgical safety. & 24 & 60.0 \\
• Total after. & 18 & 45.0 \\
\hline
\end{tabular}

Table (6) points to statistically significant relations between scrub nurses' scores of performance and their gender $(p=0.01)$, and experience years in nursing $(p=0.048)$. It is evident that the performance scores were highest among males, and those having less than ten-years experience.

Table (6): Relation between scrub nurses' performance and their characteristics $(\mathrm{N}=40)$.

\begin{tabular}{|c|c|c|c|c|}
\hline & \multicolumn{2}{|c|}{ Practice score } & \multirow{2}{*}{$\begin{array}{c}\text { Mann } \\
\text { whitney } \\
\text { test }\end{array}$} & \multirow{2}{*}{$\begin{array}{c}p- \\
\text { value }\end{array}$} \\
\hline & Mean \pm SD & Median & & \\
\hline \multicolumn{5}{|l|}{ Age: } \\
\hline$<39$ & $65.5 \pm 15.9$ & 62.80 & & \\
\hline $40+$ & $72.5 \pm 15.8$ & 77.75 & 2.75 & 0.10 \\
\hline \multicolumn{5}{|l|}{ Gender: } \\
\hline Male & $79.4 \pm 3.0$ & 79.30 & & \\
\hline Female & $65.1 \pm 16.2$ & 62.20 & 6.33 & $0.01^{*}$ \\
\hline \multicolumn{5}{|l|}{ Nursing qualification: } \\
\hline Technical school of nursing & $65.6 \pm 17.7$ & 61.30 & & \\
\hline Bachelor & $68.7 \pm 13.3$ & 68.40 & 1.26 & 0.26 \\
\hline \multicolumn{5}{|l|}{ Years experience in nursing: } \\
\hline$<5$ & $69.0 \pm 17.7$ & 67.00 & & \\
\hline $5-$ & $67.3 \pm 12.4$ & 69.90 & $\mathrm{H}=5.98$ & $0.048 *$ \\
\hline $10+$ & $49.2 \pm 4.4$ & 49.80 & & \\
\hline \multicolumn{5}{|l|}{$\begin{array}{l}\text { Attended courses in: } \\
\text { - Operation room work: }\end{array}$} \\
\hline $\begin{array}{l}\text { - Operation room work: } \\
\text { No }\end{array}$ & $67.9 \pm 17.0$ & 67.20 & & \\
\hline Yes & $62.4 \pm 8.4$ & 65.50 & 0.43 & 0.51 \\
\hline \multicolumn{5}{|l|}{ - Patient safety: } \\
\hline No & $58.0 \pm 10.8$ & 54.45 & & \\
\hline Yes & $69.2 \pm 16.3$ & 67.40 & 3.79 & 0.052 \\
\hline \multicolumn{5}{|l|}{ - Management/administration: } \\
\hline No & $67.6 \pm 16.3$ & 67.20 & & \\
\hline Yes & $58.6 \pm 5.2$ & 59.30 & 1.06 & 0.30 \\
\hline
\end{tabular}

*: Statistically significant at $p<0.05$. H: Kruskal wallis test. 
Table (7) demonstrated generally low performance of circulating nurse before operation. Except for a few items such as communicating and collecting with other health care team members (100\%), communication with the patient $(92.5 \%)$, ensuring patient preparation in the department $(67.5 \%)$, all the other items were performed by less than two third of them. The performance was particularly low in the items of checking preanesthesia sheet and American society of anesthesia score (ASA score), which was done by none of them. Moreover, the items of confirming side rails are up and secure during patient transport, and using lifting and not dragging while transporting patient to and from the table of operations were performed by only one of them $(2.5 \%)$.

Table (7): Percentage distribution of circulating nurses' performance before operating room $(\mathrm{N}=40)$.

\begin{tabular}{|c|c|c|}
\hline \multirow{2}{*}{ Circulating nurse performance } & \multicolumn{2}{|c|}{ Done } \\
\hline & $\mathrm{N}$ & $\%$ \\
\hline \multicolumn{3}{|l|}{ Before operation: } \\
\hline \multicolumn{3}{|l|}{ Infection control: The circulating nurse: } \\
\hline - Ensures the cleanliness of the operating room. & 26 & 65.0 \\
\hline - Prepares sterile instruments for scrub nurse. & 26 & 65.0 \\
\hline - Keeps area sterile from any contamination. & 21 & 52.5 \\
\hline \multicolumn{3}{|l|}{ Surgical safety (sign in): } \\
\hline $\begin{array}{l}\text { - Identifies patient in a true manner (ask patient } \\
\text { about full name, file number and bracelets on } \\
\text { his/her wrist by same data). }\end{array}$ & 5 & 12.5 \\
\hline $\begin{array}{l}\text { - Check the signing of the consent form in which } \\
\text { the patient agrees for the surgery and anesthesia. }\end{array}$ & 23 & 57.5 \\
\hline - Checks the name of operation. & 19 & 47.5 \\
\hline $\begin{array}{l}\text { - Checks the site of the operation and the site } \\
\text { mark. }\end{array}$ & 2 & 5.0 \\
\hline $\begin{array}{l}\text { - Checks pre-anesthesia sheet and American } \\
\text { society of anesthesia score (ASA score). }\end{array}$ & 0 & 0.0 \\
\hline \multicolumn{3}{|l|}{ Work place safety: } \\
\hline - Checks the functioning of light. & 16 & 40.0 \\
\hline - Checks the functioning of machines. & 12 & 30.0 \\
\hline $\begin{array}{l}\text { - Checks the presence of X-ray searchlight in the } \\
\text { OR. }\end{array}$ & 13 & 32.5 \\
\hline \multicolumn{3}{|l|}{ Procedure before operation: the circulating nurse: } \\
\hline - Ensures patient preparation in the department. & 27 & 67.5 \\
\hline $\begin{array}{l}\text { Ensures the existence of the results of laboratory/ } \\
\text { diagnostic test. }\end{array}$ & 15 & 37.5 \\
\hline - Assists in the transfer of the patient to the OR. & 4 & 10.0 \\
\hline $\begin{array}{l}\text { - Confirms side rails are up and secure during } \\
\text { patient transport. }\end{array}$ & 1 & 2.5 \\
\hline - Covers patient during transport. & 7 & 17.5 \\
\hline $\begin{array}{l}\text { Uses lifting and not dragging while transporting } \\
\text { patient to and from the table of operations. }\end{array}$ & 1 & 2.5 \\
\hline - Makes sure patient is in the correct position. & 17 & 42.5 \\
\hline - Communicate with the patient. & 37 & 92.5 \\
\hline $\begin{array}{l}\text { - Communicates and collaborates with other health } \\
\text { care team members. }\end{array}$ & 40 & 100.0 \\
\hline - Counts sponges and gauze with scrub nurse. & 20 & 50.0 \\
\hline - Types sponges and gauze with scrub nurse. & 16 & 40.0 \\
\hline - Counts needles with scrub nurse. & 19 & 47.5 \\
\hline - Types needles with scrub nurse. & 15 & 37.5 \\
\hline - Adjust light before skin preparation. & 10 & 25.0 \\
\hline
\end{tabular}

Table (8) showed a wide variation in circulating nurses' performance during the operation. Thus, all of them $(100 \%)$ were providing instruments, equipment, and other supplies to scrub nurse as needed during operation, responded to doctor's orders in the operating room, and prepared dressing before the end of the operation. At the other extreme, none of them conducted "time out" immediately before skin incision using a surgical safety checklist, confirmed all team members have introduced themselves by name and role, or administered medications (labeling by the name of the patient, name of medication, date and preparing time).

Table (8): Percentage distribution of circulating nurses' performance during operating room $(\mathrm{N}=40)$.

\begin{tabular}{|c|c|c|}
\hline \multirow{2}{*}{ Circulating nurse performance } & \multicolumn{2}{|c|}{ Done } \\
\hline & $\mathrm{N}$ & $\%$ \\
\hline \multicolumn{3}{|l|}{ During operation } \\
\hline \multicolumn{3}{|l|}{ Infection control: The circulating nurse: } \\
\hline - Monitors sterile field during operation. & 23 & 57.5 \\
\hline - Maintains sterile field during operation. & 15 & 37.5 \\
\hline \multicolumn{3}{|l|}{ Surgical safety (time out): The circulating nurse: } \\
\hline $\begin{array}{l}\text { - Conducts "time out" immediately before skin } \\
\text { incision using a surgical safety checklist. }\end{array}$ & 0 & 0.0 \\
\hline $\begin{array}{l}\text { - Confirms all team members have introduced } \\
\text { themselves by name and role. }\end{array}$ & 0 & 0.0 \\
\hline $\begin{array}{l}\text { - Confirms antibiotic prophylaxis are given within } \\
\text { the last } 60 \mathrm{~min} \text {. }\end{array}$ & 21 & 52.5 \\
\hline \multicolumn{3}{|l|}{$\begin{array}{l}\text { Surgical safety (sign-out) nurse verbally confirms } \\
\text { with team: }\end{array}$} \\
\hline - The name of the procedure recorded. & 10 & 25.0 \\
\hline - The instruments, sponges and needles are correct. & 18 & 45.0 \\
\hline - How the specimen is labeled. & 25 & 62.5 \\
\hline \multicolumn{3}{|l|}{ Workplace safety: The circulating nurse: } \\
\hline - Creates a safe environment. & 35 & 87.5 \\
\hline - Maintains a safe environment. & 18 & 45.0 \\
\hline \multicolumn{3}{|l|}{ Procedure during operation: The circulating nurse: } \\
\hline $\begin{array}{l}\text { - Provides emotional support to patient prior to } \\
\text { induction of anesthesia. }\end{array}$ & 36 & 90.0 \\
\hline - Assists the anesthesiologist in intubation. & 23 & 57.5 \\
\hline $\begin{array}{l}\text { - Provides instruments, equipment, and other } \\
\text { supplies to scrub nurse as needed during } \\
\text { operation. }\end{array}$ & 40 & 100.0 \\
\hline $\begin{array}{l}\text { - Administers medications (labeling by the name } \\
\text { of the patient, name of medication, date and } \\
\text { preparing time). }\end{array}$ & 0 & 0.0 \\
\hline $\begin{array}{l}\text { - Records the gauze, sponges and instruments in } \\
\text { OR count sheet. }\end{array}$ & 6 & 15.0 \\
\hline - Responds to doctor's order in the OR. & 40 & 100.0 \\
\hline - Monitors patient positioning. & 2 & 5.0 \\
\hline - Prepares dressing before the end of the operation. & 40 & 100.0 \\
\hline $\begin{array}{l}\text { - Informs OR head nurse of any special events } \\
\text { during operation. }\end{array}$ & 27 & 67.5 \\
\hline
\end{tabular}

Table (9) displayed, circulating nurses' performance of infection control after the operation was low. It ranged between (22.5\%) for supervising cleansing of OR floor by the housekeeper to $(65.0 \%)$ for cleaning the table and all surfaces of instruments. As for the performance of the procedure after the operation, the table showed generally high levels of circulating nurses' performance. It 
reached $(100.0 \%)$ for for rearranging OR after operation.

Table (9): Percentage distribution of circulating nurses' performance after operating room $(\mathrm{N}=40)$.

\begin{tabular}{llr}
\hline & \multicolumn{2}{c}{ Done } \\
\cline { 2 - 3 } Circulating nurse performance & $\mathrm{N}$ & $\%$ \\
\hline $\begin{array}{l}\text { After operation: } \\
\text { Infection control: The circulating nurse: }\end{array}$ & 23 & 57.5 \\
- Cleans the ventilator after operation. & 26 & 65.0 \\
- Cleans the table and all surfaces of instruments. \\
- Supervises cleaning of OR floor by housekeeper. & 9 & 22.5 \\
Procedure after operation: The circulating nurse: & & \\
- Labels the specimens (including the patient & 34 & 85.0 \\
$\quad$ name). & 34 & 85.0 \\
- Cleans patient from the blood and changes gown & & \\
$\quad$ if needed. & 34 & 85.0 \\
- Closes an oxygen set and all machines after the \\
$\quad$ operation.
\end{tabular}

Table (10) demonstrated that the performance of the circulating nurses was low. It was lowest before the operation were none of them $(0.0 \%)$ had adequate performance. The performance after the operation was the highest, although slightly more than one-third of the circulating nurses had adequate total performance after the operation $(37.5 \%)$.

Table (10): Total percentage distribution of circulating nurses performance $(\mathrm{N}=40)$.

\begin{tabular}{|c|c|c|}
\hline \multirow{2}{*}{ Circulating nurse performance } & \multicolumn{2}{|c|}{ Done } \\
\hline & $\mathrm{N}$ & $\%$ \\
\hline $\begin{array}{l}\text { Before operation: } \\
\text { - Infection control. } \\
\text { - Surgical safety. } \\
\text { - Workplace safety. } \\
\text { - Procedure before operation. } \\
\text { - Total before. }\end{array}$ & $\begin{array}{l}11 \\
0 \\
3 \\
1 \\
0\end{array}$ & $\begin{array}{l}27.5 \\
0.0 \\
7.5 \\
2.5 \\
0.0\end{array}$ \\
\hline $\begin{array}{l}\text { During operation: } \\
\text { - Infection control. } \\
\text { - Surgical safety (time-out). } \\
\text { - Surgical safety (sign-out). } \\
\text { - Workplace safety. } \\
\text { - Procedure before operation. } \\
\text { - Total during. }\end{array}$ & $\begin{array}{l}15 \\
0 \\
2 \\
18 \\
4 \\
2\end{array}$ & $\begin{array}{l}37.5 \\
0.0 \\
5.0 \\
45.0 \\
10.0 \\
5.0\end{array}$ \\
\hline $\begin{array}{l}\text { After operation: } \\
\text { - Infection control. } \\
\text { - Procedure after operation. } \\
\text { - Total after. }\end{array}$ & $\begin{array}{l}2 \\
33 \\
15\end{array}$ & $\begin{array}{l}5.0 \\
82.5 \\
37.5\end{array}$ \\
\hline
\end{tabular}

Table (11) demonstrated statistically significant relations between circulating nurses' scores of performance and their age $(p=0.004)$, gender $(p=$ $0.01)$, nursing qualification $(p=0.04)$, and attendance of training in operating room work $(p=0.03)$. It can be noticed that the performance score were highest among those aged 40 or older, males, holding a bachelor degree, and those having no attendance of training in the operation room work.
Table (11): Relation between circulating nurses' performance and their characteristics.

\begin{tabular}{|c|c|c|c|c|}
\hline & \multicolumn{2}{|c|}{ Practice score } & \multirow{2}{*}{$\begin{array}{c}\text { Mann } \\
\text { whitney } \\
\text { test }\end{array}$} & \multirow{2}{*}{$\begin{array}{c}p- \\
\text { value }\end{array}$} \\
\hline & Mean \pm SD & Median & & \\
\hline \multicolumn{5}{|l|}{ Age: } \\
\hline$<39$ & $47.1 \pm 13.6$ & 48.10 & & \\
\hline $40+$ & $62.7 \pm 10.5$ & 62.70 & 8.42 & $0.004 *$ \\
\hline \multicolumn{5}{|l|}{ Gender: } \\
\hline Male & $65.3 \pm 6.1$ & 62.40 & & \\
\hline Female & $47.6 \pm 13.8$ & 48.10 & 6.12 & $0.01 *$ \\
\hline \multicolumn{5}{|l|}{ Nursing qualification: } \\
\hline Technical school of nursing & $46.1 \pm 14.6$ & 41.90 & & \\
\hline Bachelor & $54.9 \pm 12.6$ & 56.20 & 4.38 & $0.04^{*}$ \\
\hline \multicolumn{5}{|l|}{ Years experience in nursing: } \\
\hline$<5$ & $53.2 \pm 12.9$ & 54.60 & & \\
\hline 5- & $45.7 \pm 15.2$ & 40.35 & 2.32 & 0.13 \\
\hline \multicolumn{5}{|l|}{ Attended courses in: } \\
\hline $\begin{array}{l}\text { - Operation room work: } \\
\text { No }\end{array}$ & $52.0 \pm 13.5$ & 53.30 & & \\
\hline Yes & $39.7 \pm 14.7$ & 32.50 & 4.95 & $0.03^{*}$ \\
\hline \multicolumn{5}{|l|}{ - Patient safety: } \\
\hline No & $41.5 \pm 11.2$ & 39.20 & & \\
\hline Yes & $51.9 \pm 14.4$ & 56.05 & 2.64 & 0.10 \\
\hline \multicolumn{5}{|l|}{ - Management/administration: } \\
\hline No & $50.5 \pm 14.5$ & 52.0 & & \\
\hline Yes & $42.0 \pm 10.3$ & 39.60 & 0.90 & 0.34 \\
\hline
\end{tabular}

*: Statistically significant at $p<0.05$. H: Kruskal wallis test.

\section{Discussion}

A main objective of the present study was to assess scrub/circulating nurses' performance in ORs. The sample of such nurses consisted of a majority of females, with range age 23.0-43.0 years and mean \pm SD $27.6 \pm 3.5$, and range experience $1.0-25.0$ years and mean \pm SD $4.6 \pm 4.4$, and mostly with diploma degree. Moreover, only a few of them reported having previously attended training courses in OR work or in management, although a majority attended training in infection control and patient safety. Thus, more than half of these nurses have technical school of nursing qualification, a few years of experience, and no specialized training in OR work.

Concerning scrub nurses' performance of infection control before the operation, most of them were observed to perform basic tasks as wearing shoes dedicated to OR, and washing hands prior to gowning. However, the performance of other important tasks was deficient so that none of them made sure all team members carried out the correct hand wash, and around one-third were observed to wear head covers or masks properly, or washed their hands in the right way. Thus, only less than one-fourth of them had adequate performance of infection control before the operation, although all of them reported having had previous training in 
infection control. The finding raises much concern given the risks of lack of compliance with infection control policies and procedures on patients, particularly in ORs. Similar findings were reported by Ahmed [9] who found that the scrub nurses in Ain Shams University Hospital did not carry out the surgical hand wash according to the standard.

The scrub nurses' performance of the procedure before the operation were not satisfactory as the majority of scrub nurses not counts the cables of diathermy with circulating nurses, that is because most of them not oriented about communication skills. Thus, although the task of selection of instruments, equipment, and supplies appropriate for the surgery was performed by all of them, the tasks of counting and checking equipment were observed to be done by half of them. In total, around one-third of them had adequate performance of the procedure before the operation. The deficient performance of these steps can lead to unexpected problems during the surgery.

Furthermore, the performance of infection control by the current study scrub nurses during the operation was similarly low as before the operation, with only less than one-fourth of them having adequate total performance. The major deficiencies were related to not helping doctors in wearing the protective barrier equipment, this may be related to the community culture, and they were not putting sterile dressing on the operation site. These could be attributed to the willingness of the doctor to be helped by the scrub nurse, and to role ambiguity regarding putting the sterile dressing on operation site, which might be considered by some as a doctor's role, also, this may be the result of a number of reasons, including the lack of attention of nurses during the training of infection control procedures, the lack of complete information in the trainer, the inability of the trainer to communicate information to the trainees or the nurses do not know the role to do. For this, Birks et al., [10] in a study in Australia stressed the importance of clarifying the scope of practice for nurses in their roles in order to avoid any ambiguities or role conflict.

As regards the current study scrub nurses' performance of the procedure during the operation, the results showed a very low percentage of total adequate performance. This was mainly due to failure of the scrub nurse to put used abdominal towels in a special container, which was observed to be done by only one of them. This could be attributed to the lack-of such containers in some of the rooms, or to neglect from the nurse side. In agreement with this, a study in El-Miniya University Hospitals by Ali [11] found that only a minority of the scrub nurses was observed to dispose of the used abdominal towels in a special container.

The current study scrub nurses' performance of surgical safety (sign-out) during the operation was also deficient. The items were concerned with counting gauze and sponges, instruments before closing the peritoneum of the skin with the surgeon and circulating nurse. This could also be due to role ambiguity between the scrub and circulating nurse. In this regard, Gibbs [12] Stresses that a surgeon and a nurse are the primary defenders against retention of small miscellaneous items and device fragments, sharps/needles and instruments. Behavior change training is recommended to actually use standard safe practices that will prevent patient harm.

The scrub nurses' performance of infection control after the operation was better compared to before and during, with almost two-thirds of them have adequate total performance. Nonetheless, still more than two-thirds of them did not remove their gowns before exit from OR, and did not wash their hands after removing protective barrier equipment. This could be attributed to the pressure of time to end-up with all the other tasks after the operation. A similarly low rate of adherence to hand hygiene rules was reported in a study among nurses in Finland Laurikainen [13]. A low compliance to hand washing was also demonstrated among nurses in Alexandria, and it was attributed to that nurses linked the need for hand hygiene to a sense of dirtiness Lohiniva [14].

Concerning scrub nurses' performance in surgical safety after the operation, the present study results indicated that almost two-thirds of them had adequate performance. Nonetheless, still around two-fifth of them were not observed to collect towels, covers and put them in a special container. This indicates some carelessness among these scrub nurses, which may carry some risks of the spread of infections. In agreement with this, a study in Bangladesh [15] revealed a low compliance among nurses in disposing of used materials in special containers, and this was attributed to lack of resources and facilities.

Overall, only approximately one-third of the scrub nurses in the current study had total adequate performance throughout the three phases of the operations.

The higher performance was among males, and those having less than ten-year of experience could 
have more than one explanation. The first is that male nurses are generally newcomers in the nursing profession, and thus may tend to exert more efforts to show their competency in performing their jobs. The second is that the nurses with long years of experience could become more relaxed in strictly following the policies and procedures. In congruence with this, a study in the United States demonstrated that the performance of scrub nurses correlated positively with the years of experience Koh [16]

The present study additionally assessed the performance of the circulating nurses in the ORs. The results demonstrated generally low performance before the operation. Thus, none of them had adequate surgical safety or total performance before the operation, and only one had adequate performance of the procedures before operation. The major deficiencies were with identifying patient in true manner, checking pre-anesthesia sheet and ASA score (American society anesthesiologist score), confirming side rails are up and secure during patient transport, using lifting and not dragging while transporting patient to and from the table of operations, and covering patient during transport. Such deficiencies may expose the patient to risk of falling, in addition to the untoward consequences of false identification of the patient. They reflect neglect that could be attributed to the lack of a system for reward or punishment for application of the related policies.

In line with the foregoing, Fuller [17] emphasized the importance of the steps that should be taken to prevent wrong-site, wrong person, wrong procedure errors, starting with structured communication between the patient, the surgeon(s), the nurse(s), and other team members of the health care team. Thus, prevention of surgical errors requires the attention of all personnel involved in the patient's care. Therefore, every one of the team must know and understand the policies and procedures of the department he/she works in.

The circulating nurses' performance during the operation was similarly low, with only two of them have total adequate performance. The highest performance during the operation was related to infection control and workplace safety. Conversely, the lowest was for surgical safety in time-out and sign-out. Thus, none of them conducted timeout immediately before skin incision using a checklist, or confirmed all team members have introduced themselves by name and role. This could be due to the lack of such checklist. Moreover, the nurse could be embarrassed to ask all team members, including the surgeons, to introduce themselves by name and role if they are not willing to do it. These results do not comply with the WHO Surgical Safety Manual [18], which recommends sign-out during or immediately after wound closure, before moving the patient out of the operating room, whilst surgeon is still present. The circulating nurse should confirm the operation performed and record it, check that instruments, sponges/swabs and needle counts are complete, and check that surgical specimens are labelled correctly.

Furthermore, none of the circulating nurses in the current study administered medications to patients with labeling by the name of the patient, name of medication, date and preparing time as a part of the procedure of the operation. This could" be due to that the anesthesiologist might be responsible for this task. Similarly, the deficiency in monitoring patient positioning during the operation could be due to that the assistant surgeon might be responsible for it. In this respect, the Patient Safety Goals (2016) [19] described how to use medications safely before a procedure, and label medicines that are not labeled, e.g. medicines in syringes, cups and basins.

The performance of the circulating nurses in the present study after the operation was better compared to before and during, with slightly more than one-third of them having total adequate performance. Nonetheless, their performance of the procedure during the operation was far better than their performance of infection control. Only two (5\%) of them had adequate performance of infection control after the operation, compared with around one-third before and during the operation. This could be attributed to the misconception that infection control is more important before and during the operation. It could also be to hurrying-up to prepare for the next operation at the expense of compliance to infection control standards and guidelines. In agreement with this. Ali [21] in a study in El-Miniya found that circulating nurses did not supervise the process of cleaning the OR, which may cause a failure to follow infection control measures.

Overall, only one of the forty circulating nurses in the present study had adequate total performance.

All above-mentioned results, related to the performance of nurses as possible that is interpreted to be due the absence of clear regulations or guidelines and common procedures as well as the absence of training and education programs for the operating room nurses. 


\section{Conclusion:}

The findings of the study indicate major deficiencies in OR general policies in the study settings, with a wide discrepancy between what is reported and what is observed. The infrastructure is generally adequate except for environmental safety infrastructure. Scrub nurses' performance is mostly inadequate, particularly during the operation, and is influenced by the working OR, gender, and experience years. The circulating nurses' performance is worse, especially before the operation, and is related to the working OR, age, gender, nursing qualification, and attendance of training in operating room work.

\section{Recommendations:}

Based on the findings of the study, the following is recommended.

\section{For the organization:}

- A nursing quality management system must be initiated in hospital, to help in achieving compliance with the structural and process standards.

- The OR nurses need a better orientation about the related nursing standards; this could be through the nursing quality care committee.

- Written and clear job description should be disseminated and communicated to all categories, with a defined job title, department or division where the job is located, and relationship of the job to other jobs.

- On-the-job programs for training OR nurses are recommended, particularly regarding invasive interventions and administrative procedures required.

- The hospital administration needs to improve the environmental safety infrastructure.

\section{For the nursing director:}

- Ensure that the Quality Care Committee meets at least monthly to identify the needs of the nurses in order to improve their administrative and technical practices.

- Manual of nursing policies and procedures must be made available and used by each nurse, with supervision on application. Changes in policies and roles should be communicated to all nurses to avoid job ambiguity or conflict.

- Continuing training activities are needed to refresh OR nurse's knowledge and performance.

- Close supervision is recommended to ensure staff nurses accurate and detailed documentation of patients' data and information.

\section{For the head nurse in operating room:}

- Manual of nursing policies and procedures must be made available and used by each OR nurse, with supervision on application.

- Ensure that the new nurses are carried out orientation period of: Infection control practices, patient and environmental safety, and surgical skills.

- Ensure staff nurses were providing accurate and detailed documentation of patients.

- Ensure and manage all devices and materials, environmental safety, and infection control.

- Share knowledge through experience/facilitating learning.

- Organize triage and emergency responses in the operating room.

- Supervise practice of the staff.

- Incidence reports must be available and applicable for each nurse in the operating room, which will help to diminish or avoid faults in their actions.

\section{For research:}

An intervention study is proposed to examine the effect of training activities on OR nurses' performance.

\section{References}

1- RUMANE A.: Quality management instruction projects, 2011.

2- DLUGEACZ Y.: Introduction to health care quality, theory, methods, and tools, John Wiley \& Sons, Inc. p. 4, 5, 13 2017.

3- MOTACKI K. and BURKE K.: Nursing delegation and management of patient care, p. 7, 2017.

4- PHILLIPS N.: Berry and Kohn's operating room technique, $12^{\text {th }}$ ed, section four, the perioperative environment, $p$. 176, 2013.

5- SHORAN J.: Roles nurses play that truly make them the heart of health care, from www.nurse together.com , 2014.

6- YODER-WISE P.: Leading and management in nursing, $6^{\text {th }}$ ed, p. 119, 138, 2015.

7- HABASHY M.A.: Patients' satisfaction with quality of care services at cardiac catheterization unit at Suez Canal University Hospital in Ismaillia. Mscthesis, Faculty of Nursing, Suez Canal University, 2013.

8- REFAY M.M.: Potential hazards in the operating room: Proposed guidelines for safety in the operating room. Master thesis, Faculty of nursing, Cairo University, 2006.

9- AHMED M.: Work related hazards facing healthcare team in the operating room. Thesis for master degree. Fauclty of Nursing. Ain Shams University, 2014.

10- BIRKS Y., HEYHOE J., HARRISON R., O'HARA J., CRACKNELL A., LAWTON R.: The role of emotional patient safety, 2016. 
11- ALI R.: Nurses performance at operating room at ElMiniya University Hospitals, master thesis, Faculty of Nursing, Cairo University, 2015.

12- GIBBS and VERNA C.: NoThing Left Behind, Prevention of Retained Surgical Items Multi-stakeholder Policy. http ://www.nothingle ftb ehind. org, 2013.

13- LAURIKAINEN E., RINTALA E., KAARTO A.M. and ROUTAMAA M.: Adherence to surgical hand rubbing directives in a hospital district of Southwest Finland, 2016.

14- LOHINIVA A.L., BASSIM H., HAFEZ S., KAMEL E., AHMED E., SAEED T. and M. TALAAT: Determinants of hand hygiene compliance in Egypt: Building blocks for a communication strategy, 2015.

15- RIMI N.A., ISLAM M.S., LUBY S.P., SULTANA R.,
ZAMAN R.U. and UDDIN M.: Family caregivers in public tertiary care hospitals in Bangladesh: Risks and opportunities for infection control. Am. J. Infect. Control. www.ajicjournal.org/article/S0196-6553(14)000960/fulltext, 2014.

16- KOH R.Y., PARK T. and WICKENS C.: An investigation of differing levels of experience \& incidices, 2014.

17- FULLER J.: Surgical technology. Principles and practice, $7^{\text {th }}$ Ed, p. 67, 2017.

18- Implementation manual-WHO surgical safety checklist, first Ed, 2008.

19- Hospital Patient Safety Goals, 2016.

20- ALI R.: Nurses performance at operating room at ElMiniya University Hospitals, master thesis, Faculty of Nursing, Cairo University, 2015.

\section{جودة الرعاية التمريضية المقلدمة للمرضى فى غرف العمليات

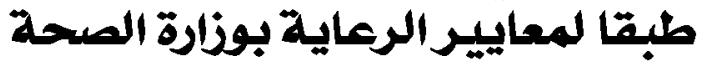

شهد القطاع الصحى في الآونة الآخيرة إهتماما كبيرا على جميع المستويات حيث آصبح موضوع جودة الرعاية الصحية محل إهتمام

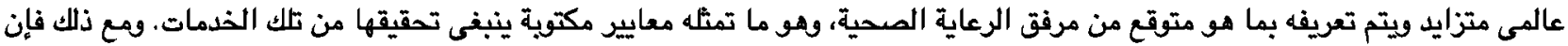

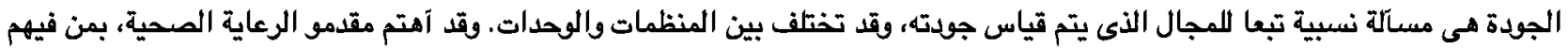

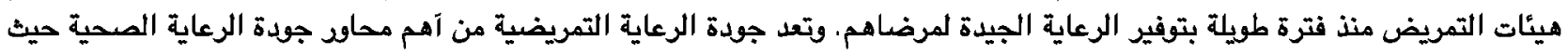

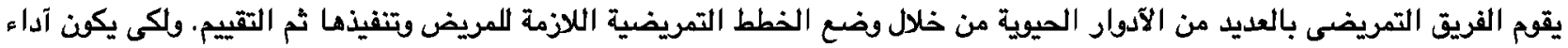

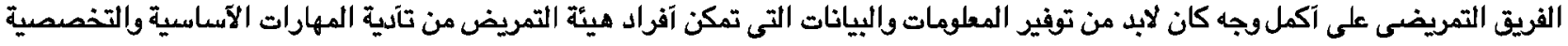

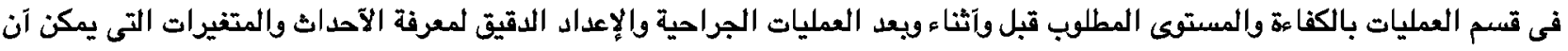

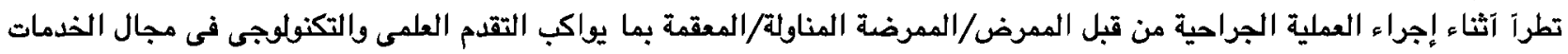

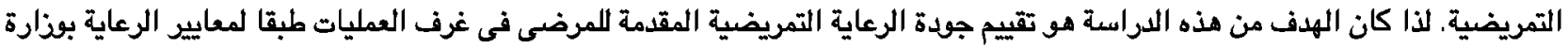

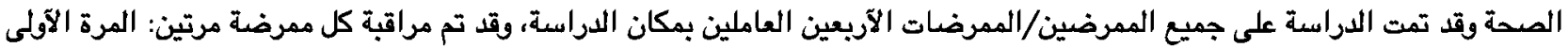

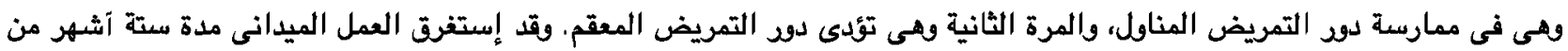

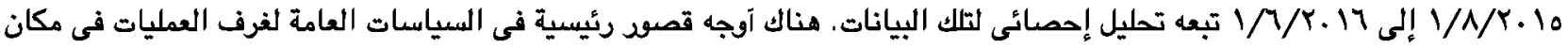

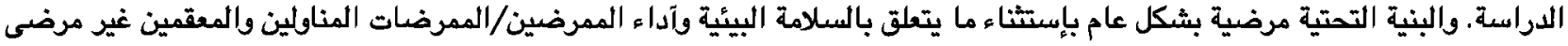

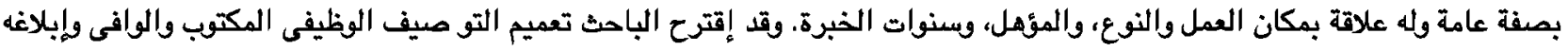

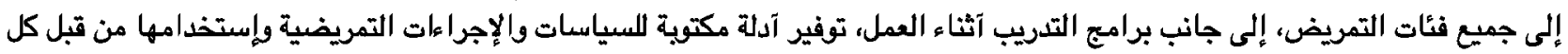

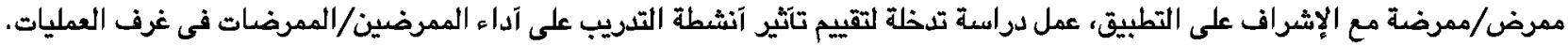

